\title{
Epidemiological profile of dengue in Brazil between the years 2014 and 2019
}

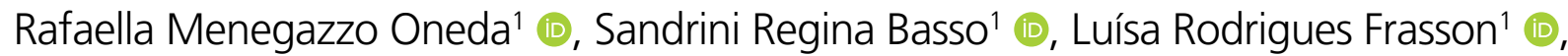 \\ Nicole Meller Mottecy ${ }^{1}$ (D), Leonardo Saraiva ${ }^{2 *}$ (D), Cíntia Bassanii,4
}

\section{SUMMARY}

OBJECTIVE: The aim was to determine the epidemiological profile of dengue fever in Brazil between the years 2014 and 2019. METHODS: This is an observational, descriptive, cross-sectional, and retrospective study, which was carried out through the analysis of secondary data collected from the National System of Notification Appeals (SINAN) and from SUS Computer Department (DATASUS). RESULTS: The total number of reported cases was 5,867,255, and 2015 was the year with the highest cases $(1,696,340)$. The cases were predominant in the Southeast and Midwest macro-regions, the female sex (55.6\%), brown people (48\%), and clinical and epidemiological criteria of confirmation (63.8\%). Regarding the age group, it was observed that during the study period, the highest prevalence occurred in individuals between 20 and 39 years (38.3\%). There was a change of serotype from DENV-1 to DENV-2, and dengue was the most prevalent classification (95.2\%). Concerning hospitalization rates, there was a limited necessity of admissions (5.7\%), as well as few deaths due to the notified disease $(3,444)$.

CONCLUSIONS: There was a significant growth in the number of dengue fever cases in Brazil in 2019, which represents a public health problem. KEYWORDS: Dengue. Aedes aegypti. Incidence. Health profile.

\section{INTRODUCTION}

Dengue is one of the main endemic diseases in Brazil. It is an arbovirus, transmitted via the bite of the Aedes aegypti mosquito, and can be divided into four different serotypes: DENV-1, DENV-2, DENV-3, and DENV-4 ${ }^{1}$. The first report of dengue in Brazilian territory dates back to the end of the 19th century, but only in 1981 it was possible to isolate the serotypes of the virus, which has since spread throughout the country ${ }^{2}$.

The classification scheme of dengue divides the disease into three different categories. The first, dengue without warning signs, has as initial and main symptom that includes the abrupt onset of a high fever $\left(39-40^{\circ} \mathrm{C}\right)$ in association with severe headache, myalgia, arthralgia, and retro-orbital pain. Patients may also manifest maculopapular rash, anorexia, diarrhea, nausea, and vomiting. The symptoms usually improve after the third day of their onset ${ }^{3}$.

Some patients, after defervescence of fever, may progress to dengue with warning signs, the second category of the disease, presenting severe and continuous abdominal pain, persistent vomiting, pleural and/or pericardial effusion, ascites, postural hypotension, hepatomegaly, mucosal bleeding, lethargy, irritability, and progressive increase in hematocrit. These manifestations must always be investigated, since they can lead to the third and most dangerous category, severe dengue, promoting a range of outcomes including shock, hemorrhage, organs dysfunction and even death ${ }^{3,4}$.

\footnotetext{
${ }^{1}$ Faculdade Meridional de Passo Fundo - Passo Fundo (RS), Brazil.

¿Universidade de Passo Fundo - Passo Fundo(RS), Brazil.

${ }^{3}$ Faculdade Meridional de Passo Fundo - Passo Fundo (RS), Brazil.

${ }^{4}$ Hospital Servidor Público Estadual de São Paulo - São Paulo (SP), Brazil.

*Corresponding author: leo77saraiva@hotmail.com

Conflicts of interest: the authors declare there is no conflicts of interest. Funding: none.

Received on February 03, 2021. Accepted on March 14, 2021.
} 
The definitive diagnosis of dengue is performed in laboratory through the serology and viral antigen detection test. Since it is not possible to obtain the results of the tests immediately, the World Health Organization (WHO) recommends that the tourniquet test should be performed during the screening of all patients under the suspect of dengue and without the signs of bleeding ${ }^{4,5}$.

The control of $A$. aegypti is the main form of disease prevention. From the above findings, it is clear that dengue is a problem that needs to be tackled in Brazil ${ }^{6}$. This study aimed to trace the epidemiological profile of the disease in the country between the years 2014 and 2019 .

\section{METHODS}

This is an observational, descriptive, cross-sectional, and retrospective study. Data collection was performed using the information available at Notifiable Diseases Information System (SINAN) and at SUS Department of Informatics (DATASUS), in the period between January 1, 2014 and December 31, 2019. Through them, the relation between Brazilian macro-regions and the following variables were observed: the number of probable cases, serotypes, sex, race, age group, final diagnosis, disease progression, need for hospitalization, and the confirmation criteria of the disease.

Statistical analysis was performed using SPSS V20, Minitab 16, and Excel Office 2010 software. This study has a significance level of 0.05 ; therefore, all confidence intervals also met $95 \%$ of statistical confidence.

Since the data collection was performed online, and all the data are available at SINAN website and are of public domain, this research is, thereby, free of ethical risks.

\section{RESULTS}

In the period between 2014 and 2019, 5,868,413 suspected cases of dengue were identified in Brazil. The highest number of notifications occurred in 2015 ( $\mathrm{n}=1,696,340)$, followed by 2019 ( $\mathrm{n}=1,557,452), 2016$ ( $\mathrm{n}=1,514,873), 2014$ ( $\mathrm{n}=591,128), 2018$ $(\mathrm{n}=265,372)$, and $2017(\mathrm{n}=243,248)$. Comparing the years of 2014 and 2019, the incidence of dengue increased from 291.5 to 741.12 cases per 100,000 inhabitants, as shown in Figure 1.

Among the analyzed macro-regions, the incidence per 100,000 inhabitants was higher in the Midwest $(\mathrm{n}=981,320)$, followed by the Southeast $(n=3,378,636)$, Northeast $(n=1,112,369)$, North $(\mathrm{n}=195,550)$, and the South $(\mathrm{n}=200,525)$ regions (Figure 2).

Regarding the sex of the evaluated population, the males represented 2,599,974 (44.4\%) cases, while the females represented 3,258,284 (55.6\%) cases. As for the age group, the highest prevalence occurred in individuals between 20 and 39 years (38.3\%).

Concerning the race, the brown skin prevailed in the North, Northeast, and Midwest (80.7, 78.5, and 57.8\%, respectively) regions, while in the Southeast and the South regions the most affected populations were the whites.

This study also considered the need for hospitalization, which, overall, was low, but had most of its occurrences in the North (10.6\%) and the Northeast (9.6\%) regions. As for the disease progression, most patients got cured $(n=4,275,802)$, and a total of 3,444 people died due to the disease during the study period.

In the matter of serotypes, DENV-1 prevailed (87.5\%) between 2014 and 2017. However, in 2018 and 2019, DENV-2 was the most detected serotype in the country (63\%). DENV3 , the least common of them, was responsible only for 7 cases in the North, 28 in the Northeast, 20 in the Southeast, 27 in the South, and 10 in the Midwest regions (Table 1).

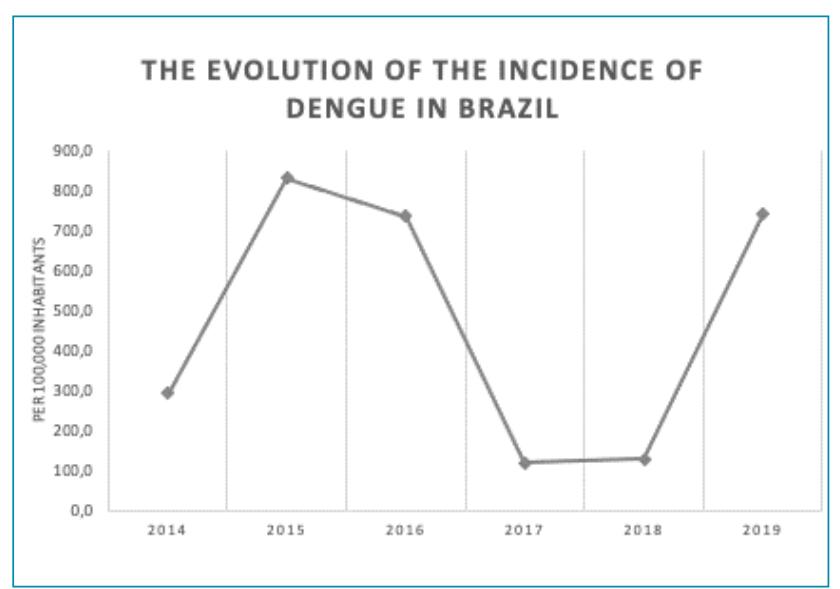

Figure 1. Evolution of the incidence of dengue in Brazil between the years 2014 and 2019.

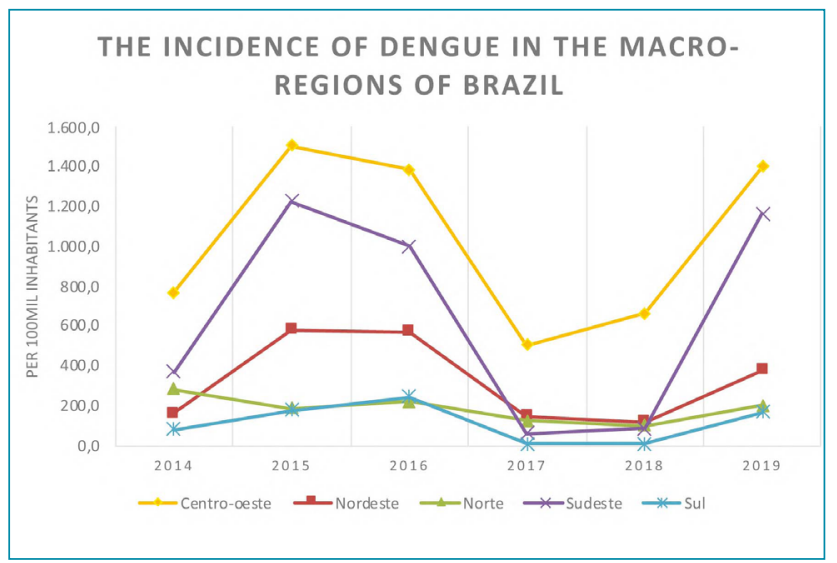

Figure 2. Incidence of dengue in the macro-regions of Brazil between the years 2014 and 2019. 
Table 1. Sociodemographic characteristics of patients with suspected dengue between 2014 and 2019 ( $n=5,868,413)$.

\begin{tabular}{|c|c|c|c|c|c|c|}
\hline Variables $n$ & 2014 & 2015 & 2016 & 2017 & 2018 & 2019 \\
\hline \multicolumn{7}{|l|}{ Suspected cases of dengue } \\
\hline Brazil & 591,128 & $1,696,340$ & $1,514,873$ & 243,248 & 265,372 & $1,557,452$ \\
\hline North & 48,302 & 32,096 & 38,543 & 21,980 & 17,668 & 36,961 \\
\hline Northeast & 90,489 & 328,713 & 325,046 & 84,830 & 66,496 & 216,795 \\
\hline Southeast & 312,181 & $1,051,063$ & 863,010 & 53,815 & 72,587 & $1,025,980$ \\
\hline South & 23,062 & 52,085 & 71,183 & 2,601 & 1,734 & 49,860 \\
\hline Midwest & 117,094 & 232,383 & 217,078 & 80,022 & 106,887 & 227,856 \\
\hline \multicolumn{7}{|l|}{ Sex } \\
\hline Males & 268,619 & 756,125 & 656,191 & 110,483 & 118,782 & 689,780 \\
\hline Females & 321,551 & 936,443 & 855,869 & 132,481 & 146,338 & 865,609 \\
\hline \multicolumn{7}{|l|}{ Age group (years) } \\
\hline $0-9$ & 48,524 & 137,191 & 125,154 & 25,304 & 29,391 & 144,128 \\
\hline $10-19$ & 106,056 & 287,183 & 251,261 & 44,668 & 45,741 & 261,263 \\
\hline $20-39$ & 235,024 & 645,383 & 574,879 & 96,936 & 102,854 & 581,937 \\
\hline $40-59$ & 146,584 & 443,178 & 382,136 & 54,431 & 63,123 & 399,684 \\
\hline $60-64$ & 20,450 & 66,966 & 57,548 & 7,578 & 8,965 & 62,187 \\
\hline $65-69$ & 14,205 & 46,843 & 41,576 & 5,602 & 6,253 & 43,521 \\
\hline $70-79$ & 15,335 & 51,780 & 46,934 & 6,097 & 6,554 & 44,175 \\
\hline$\geq 80$ & 4,723 & 16,924 & 18,426 & 2,529 & 2,396 & 15,452 \\
\hline \multicolumn{7}{|l|}{ Race } \\
\hline White & 184,046 & 549,645 & 348,773 & 38,651 & 59,057 & 506,064 \\
\hline Black & 20,788 & 52,884 & 48,749 & 6,900 & 8,537 & 64,786 \\
\hline Asian & 3,955 & 9,162 & 9,475 & 1,807 & 2,491 & 11,343 \\
\hline Brown & 165,529 & 392,875 & 427,466 & 116,667 & 114,445 & 573,710 \\
\hline Indigenous & 1,410 & 3,181 & 3,641 & 685 & 830 & 4,630 \\
\hline \multicolumn{7}{|l|}{ Serotype } \\
\hline DENV-1 & 2,340 & 5,191 & 3,785 & 283 & 456 & 4,198 \\
\hline DENV-2 & 30 & 71 & 133 & 204 & 687 & 7,972 \\
\hline DENV-3 & 12 & 23 & 42 & 9 & 3 & 10 \\
\hline DENV-4 & 611 & 358 & 106 & 51 & 12 & 398 \\
\hline DENV not informed & 588,135 & $1,690,697$ & $1,510,807$ & 242,701 & 264,214 & $1,544,874$ \\
\hline Death by dengue & 496 & 1,004 & 724 & 205 & 221 & 795 \\
\hline \multicolumn{7}{|l|}{ Final classification } \\
\hline Dengue without warning signs & 447,403 & $1,297,439$ & $1,054,127$ & 164,396 & 193,367 & $1,244,823$ \\
\hline Dengue with warning signs & 8,620 & 21,934 & 9,658 & 2,864 & 4,536 & 20,263 \\
\hline Severe dengue & 793 & 1,812 & 1,027 & 344 & 444 & 1,601 \\
\hline \multicolumn{7}{|l|}{ Confirmation criteria } \\
\hline Ignored/Blank & 85,880 & 295,623 & 398,344 & 72,585 & 63,464 & 228,148 \\
\hline Laboratory & 229,507 & 533,746 & 326,670 & 43,313 & 61,758 & 421,562 \\
\hline Clinical-epidemiological & 269,846 & 839,656 & 770,970 & 121,666 & 131,899 & 878,600 \\
\hline Under investigation & 5,895 & 27,315 & 18,889 & 5,684 & 8,251 & 24,799 \\
\hline \multicolumn{7}{|l|}{ Need for hospitalization } \\
\hline Ignored/blank & 299,990 & 929,520 & 832,166 & 110,181 & 100,045 & 558,356 \\
\hline Yes & 19,637 & 38,273 & 32,184 & 11,597 & 15,042 & 56,085 \\
\hline No & 271,501 & 728,547 & 650,523 & 121,470 & 150,285 & 943,011 \\
\hline
\end{tabular}

DENV 1, DENV 2, DENV 3, DENV 4: serotypes 


\section{DISCUSSION}

According to the $\mathrm{WHO}$, in the last decades, the incidence of dengue is increasing exponentially, especially in places near the tropics, such as the Americas and the Caribbean, and SouthEast Asia and Asia-Pacific regions ${ }^{7}$. It can be explained by factors such as the hot and humid climate, the low levels of basic sanitation, disordered urbanization, and the vector resistance to insecticides and larvicides ${ }^{8,9}$.

In this context, this study showed that, in Brazil, between 2014 and 2019, 5,867,255 cases of dengue were reported, highlighting the years of $2015(\mathrm{n}=1,696,340), 2016(\mathrm{n}=1,514,873)$, and $2019(\mathrm{n}=1,557,452)$, in which there was a significant increase of occurrences. These data are aligned with the bulletin released by WHO, in 2020, in the Epidemiological Update of Dengue and Other Arboviruses, and, in Brazil, can be explained mainly by two events: the increase of rain in these years and the introduction of a new serotype of the disease, DENV-2, which barely circulated in the country before 2018 , and, since then, has become the most prevalent serotype of dengue, as shown in this study ${ }^{10,11}$.

Still with respect to the serotype, DENV-1 predominated in 2014, 2015, 2016, and 2017 ( $\mathrm{n}=2,340,5,191,3,785$, and 283 , respectively). Despite that, the number of cases due to DENV-2, which, since 2018, became the most prevalent serotype, started to escalate already in $2017(\mathrm{n}=204)$.

Referring to the macro-regions of Brazil, two of them stood out: the Southeast region, which condensed the majority of dengue notifications ( $\mathrm{n}=3,378,636)$, and the Midwest region, which registered the highest incidence per 100,000 inhabitants. The Southeast is the most populous region of the country, which may have contributed to this being the place with the most number of notifications ${ }^{12}$.

Regarding the distribution of cases by sex, similar to what was evidenced by Martins et al. ${ }^{13}$, this study also identified that the women were the most affected by the disease $(55.6 \%)$. This cannot be explained by a single factor; however, Cardoso et al. ${ }^{14}$ believed that, in addition to spending more time indoors, a favorable environment to $A$. aegypti, women tend to seek health care more commonly than men, and consequently they are diagnosed more.

Throughout the study period, in the North, Northeast, and Midwest regions, the brown people was the most afflicted race (80.7\%, 78.5\%, and $57.8 \%$, respectively), a result confirmed by Oliveira et al. ${ }^{15}$ but opposed to what was found by Santana e Duarte ${ }^{16}$, who identified a predominance of the white race $(32.4 \%)$ in the same regions. However, in the Southeast and the South regions, the white race was more affected ${ }^{17}$.

The analysis of the age group revealed that individuals between 20 and 39 years (38.3\%) were the ones who have fallen ill mostly. These results are different than those obtained by Bravo et al. ${ }^{18}$ in the Philippines, where the most affected age group was between 5 and 14 years.

As laboratory tests are not always available, the clinical and epidemiological criterion was validated by the Ministry of Health and is usually adopted during endemics/epidemics/pandemics after the circulation of the virus is acknowledged in the area ${ }^{19}$.

Regarding the final classification of the disease, dengue without warning signs was the most prevalent $(\mathrm{n}=4,401,555)$, while dengue with warning signs $(n=67,875)$ and severe dengue $(n=6,201)$ were less common. Overall, the need for hospitalization was low, but needed the most in the North (10.6\%) and Northeast (9.6\%) regions, which burdened the public health system and highlights a failure in $A$. aegypti eradication plan ${ }^{20}$. These data are remarkably different in India where, according to Ganeshkumar et al. ${ }^{21}$, dengue is the main cause of hospitalization.

As a limitation of this study, we identified that the data were collected from a secondary source that is fueled by health professionals, who often do not fill out the forms correctly, therefore interfering in statistical analysis and results.

\section{CONCLUSIONS}

This epidemiological analysis showed that, in the period between 2014 and 2019, 5,867,255 cases of dengue were reported in Brazil, and 2015 was the year that registered the majority of notifications. The highest incidence per 100,000 inhabitants took place in the Midwest region, and most of the cases occurred in the Southeast region. There was a switch of serotype predominance which changed from DENV-1, in 2014 until 2017, to DENV-2 since then.

\section{ACKNOWLEDGMENT}

The authors thank the Institute Meridional (IMED).

\section{AUTHORS" CONTRIBUTIONS}

RMO: Conceptualization, Data curation, Investigation, Methodology, Writing - original draft, Writing - review \& editing. SRB: Conceptualization, Formal analysis, Methodology, Writing - original draft, Writing - review \& editing. LRF: Investigation, Writing - original draft, Writing - review \& editing. NMM: Conceptualization, Investigation, Writing - original draft, Writing - review \& editing. LS: Writing - review \& editing. CB: Conceptualization, Investigation, Writing - review \& editing. All authors have contributed equally to this work. 


\section{REFERENCES}

1. World Health Organization. Establishing syndromic surveillance and event-based surveillance systems for zika, dengue and other arboviral diseases. Cairo: World Health Organization. Regional Office for the Eastern Mediterranean; 2020. Available from: file:///C:/ Users/WINDOWS\%207/Downloads/9789290223443-eng.pdf.

2. Câmara FP, Theophilo RLG, dos Santos GT, Pereira SRFG, Câmara DCP, de Mattos RRC. Regional and dynamics characteristics of dengue in Brazil: a retrospective study. Rev Soc Bras Med Trop. 2007;40(2):19296. https://doi.org/10.1590/S0037-86822007000200009

3. Tsai JJ, Lin PC, Tsai CY, Wang YH, Liu LT. Low frequency of asymptomatic dengue virus-infected donor in blood centers during the largest dengue outbreak in Taiwan. PLoS One. 2018;13(10):e0205248. https://doi.org/10.1371/journal.pone.0205248

4. Brasil. Ministério da Saúde. Secretaria de Vigilância em Saúde. Departamento de Vigilância das Doenças Transmissíveis. Dengue: diagnóstico e manejo clínico: adulto e criança. Brasília: Ministério da Saúde; 2016.

5. Lum L, Ng CJ, Khoo EM. Managing dengue fever in primary care: a practical approach. Malays Fam Physician. 2014;9(2):2-10. PMID: 25893065

6. Teixeira MG, Siqueira Jr JB, Ferreira GLC, Bricks L, Joint G. Epidemiological trends of dengue disease in Brazil (2000-2010): a systematic literature search and analysis. PLoS Negl Trop Dis. 2013;7(12):e2520. PMID: 24386496

7. World Health Organization. Comprehensive guideline for prevention and control of dengue and dengue haemorrhagic fever. Revised and expanded edition. India: World Health Organization. Regional Office for South-East Asia; 2011. Available from: https:// apps.who.int/iris/bitstream/handle/10665/204894/B4751 . pdf? sequence $=1$ \&isAllowed $=\mathrm{y}$.

8. Vontas J, Kioulos E, Pavlidi N, Morou E, della Torre A, Ranson $\mathrm{H}$. Insecticide resistance in the major dengue vectors aedes albopictus and aedes aegypti. Pesticide Biochemistry and Physiology. 2012;104(2):126-31. https://doi.org/10.1016/..pestbp.2012.05.008

9. Gabriel AFB, Abe KC, Guimarães MP, Miraglia SGEK. Health impact assessment of the incidence of dengue associated with precipitation in the city of Ribeirão Preto, São Paulo. Cad Saúde Colet. 2018;26(4):446-52. https://doi.org/10.1590/1414462X201800040119

10. Pan American Health Organization. World Health Organization. Epidemiological update: dengue and other arboviruses. Pan American Health Organization. World Health Organization; 2020. Available from: file:///C:/UsersMVINDOWS\%207/Downloads/2020june-10-phe-epi-update-dengue-other-arboviruses.pdf.

11. Cao Z, Liu T, Li X, Wang J, Lin H, Chen L, et al. Individual and interactive effects of socio-ecological factors on dengue fever at fine spatial scale: a geographical detector-based analysis. Int J
Environ Res Public Health. 2017;14(7):795. https://doi.org/10.3390/ ijerph14070795

12. Johansen IC, Carmo R, Alves LC. Desigualdade social intraurbana: implicações sobre a epidemia de dengue em Campinas, SP, em 2014. Cadernos Metrópole. 2016;18(36):421-40. https://doi. org/10.1590/2236-9996.2016-3606

13. Martins MMF, Almeida AMFL, Fernandes NDR, Silva LS, Lima TB, Orrico AS, et al. Analysis of epidemiological aspects of dengue in Salvador health microregion, Bahia, the period 2007 to 2014 Espaç Saúde (Online). 2015;16(4):64-73.

14. Cardoso IM, Cabidelle ASA, Borges PCL, Lang CF, Calenti FG, Nogueira LO, et al. Dengue: clinical forms and risk groups in a high incidence city in the southeastern region of Brazil. Rev Soc Bras Med Trop. 2011;44(4):430-5. https://doi.org/10.1590/s003786822011005000044

15. Oliveira EH, Rodrigues FR, Coelho MB, Verde RMCL, Sousa FCA Epidemiological analysis of dengue cases in Maranhão state, Brazil. Research, Society and Development. 2020;9(4):e78942491. https:// doi.org/10.33448/rsd-v9i4.2491

16. Santana VTP, Duarte PM. Epidemiological profile of dengue cases registered in the municipality of Primavera do Leste-MT between 2002 and 2012. Brazilian Journal of Develpment. 2019;5(11):2750818. https://doi.org/10.34117/bjdv5n11-352

17. Instituto Brasileiro de Geografia e Estatística. Pesquisa nacional por amostra de domicílios contínua. Instituto Brasileiro de Geografia e Estatística; 2020. Available from: https://nww.ibge.gov.br/estatisticas/ multidominio/condicoes-de-vida-desigualdade-e-pobreza/17270pnad-continua.html?=\&t=o-que-e.

18. Bravo L, Roque VG, Brett J, Dizon R, L'Azou M. Epidemiology of dengue disease in the Philipphines (2000-2011): a systematic literature review. PLoS Negl Trop Dis. 2014;8(11):e3027. https:// doi.org/10.1371/journal.pntd.0003027

19. Brasil. Ministério da Saúde. Secretaria de Vigilância em Saúde. Programa Nacional de Controle da Dengue. Febre hemorrágica da dengue e apresentações graves: definição e rotina de investigação. Brasilia: Ministério da Saúde; 2010. Available from: https://www.paho.org/bra/dmdocuments/ Classificacao-de-casos-febre-hemorragica-segundo-OMSrotinas-vigilancia-epi-2010.pdf.

20. Dourado JM, Araújo CS, Godói IPD. Hospitalizations, deaths and dengue costs between 2000 and 2015 in the northern region of Brazil. Revista Brasileira Interdisciplinar de Saúde. 2020;2(4):32-9.

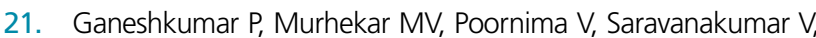
Sukumaran K, Anandaselvasankar A, et al. Dengue infection in India: a systematic review and meta-analysis. PLoS Negl Trop Dis. 2018;12(7):e0006618. https://doi.org/10.1371/journal. pntd.0006618 